\title{
SUSTENTABILIDADE E EDUCAÇÃO SUPERIOR: ANÁLISE DAS AÇÕES DE SUSTENTABILIDADE DE DUAS INSTI- TUIÇÕES DE ENSINO SUPERIOR DE SANTA CATARINA
}

\author{
SUSTAINABILITY AND HIGHER EDUCATION: ANALYSIS \\ OF SHARES OF SUSTAINABILITY OF TWO IN STITUTIONS OF \\ HIGHER EDUCATION SANTA CATARINA
}

\author{
Data de submissão: 27-11-2014 \\ Aceite: 10-08-2015 \\ Andréa Simone Machiavelli Pontes ${ }^{1}$ \\ Caroline Carneiro ${ }^{2}$ \\ David Rodrigo Petry 3 \\ Citania Aparecida Pilatti ${ }^{4}$ \\ Simone Sehnem ${ }^{5}$
}

\section{RESUMO}

Este estudo, de caráter qualitativo e descritivo, tem como objetivo compreender os conceitos de sustentabilidade e identificar como estes estão inseridos no planejamento das ações em Instituições de Ensino Superior (IES) de Santa Catarina. Para tanto, foi realizada uma breve revisão bibliográfica sobre o tema sustentabilidade, bem como sobre a relação da sustentabilidade com a educação e, posteriormente, com as IES. O problema do presente estudo consiste, assim, em identificar de que forma as IES pesquisadas estão inserindo a sustentabilidade, de maneira prática, em suas atividades institucionais. Os resultados encontrados demonstraram que as IES adotam posturas que vêm ao encontro ao contexto mundial, tanto em suas ações institucionais, incluindo a prática dos cursos oferecidos ao seu público-alvo, quanto na sua imagem perante a comunidade. Portanto, por meio da análise de documentos impressos e informações disponíveis no site institucional das IES estudadas - Serviço Nacional de Aprendizagem Comercial (SENAC/ SC) e Sociedade Educacional de Santa Catarina (SOCIESC) -, foi possível identificar que, as duas organizações se utilizam de ações e práticas para a inserção da sustentabilidade em suas atividades institucionais, o que responde prontamente ao objetivo geral deste estudo.

Palavras-chave: Sustentabilidade. Educação Superior. SENAC. SOCIESC.

1 Possui graduação em Administração pela Universidade do Contestado Caçador e mestrado profissional em Administração pela Universidade do Sul de Santa Catarina - UNISUL. Atualmente é Coordenadora do Núcleo de Ensino Superior da Faculdade SENAC de Caçador - SC, coordenando os cursos de graduação e de pós-graduação Latu-Sensu. Caçador. Santa Catarina. Brasil. E-mail: andrea. machiavellipontes@gmail.com

2 Possui graduação em Bacharelado em Turismo pelaUniversidade Luterana do Brasil - ULBRA e mestrado em Administração pela Universidade do Sul de Santa Catarina - UNISUL. Atualmente exercendo a função de Coordenadora dos Cursos Técnicos da Faculdade Sociesc Florianópolis, responsável pelos processos operacionais da Secretaria Acadêmica da Graduação e Pós-Graduação e Professora nos cursos de Graduação. Florianópolis. Santa Catarina. Brasil. E-mail: carolacarneiro@hotmail.com

3 Possui graduação em Ciências Contábeis pela Universidade do Oeste de Santa Catarina - UNOESC e mestrado profissional em andamento em Administração.

Universidade do Oeste de Santa Catarina - UNOESC. Atualmente é professor da Universidade Comunitária da Região de Chapecó, da Universidade do Oeste de Santa Catarina e do Serviço Nacional de Aprendizagem da Indústria - SENAI. Xanxerê. Santa Catarina. Brasil. E-mail: davydrodrygo@hotmail.com

4 Possui graduação em Ciências Contábeis pela Faculdades Reunidas De Administração, Ciências Contábeis E Ciências Econômicas e mestrado profissional em andamento em Administração pela Universidade do Oeste de Santa Catarina - UNOESC. Xanxerê. Santa Catarina. Brasil. E-mail: citaniapilatti@hotmail.com

5 Possui graduação em Agronegócios pela Universidade do Oeste de Santa Catarina - Campus de São Miguel do Oeste, graduação em Administração pela Universidade do Oeste de Santa Catarina - Campus de São Miguel do Oeste, mestrado em Administração pela Universidade Federal de Santa Catarina - UFSC e doutorado em Administração e Turismo pela Universidade do Vale do Itajaí - UNIVALI. Atualmente é Professora e Pesquisadora na Universidade do Oeste de Santa Catarina (UNOESC) no Mestrado Profissional em Administração. Chapecó. Santa Catarina. Brasil. E-mail: simone.sehnem@unoesc.edu.br 


\begin{abstract}
This qualitative and descriptive study, aims to understand the concepts of sustainability and identify how they are included in the action planning of Higher Education Institutions (HEI) of Santa Catarina. Therefore, a brief literature review on the topic of sustainability was held and on the relationship of sustainability with education and later with the HEI. The problem of this study consists in identify how the surveyed HEls are inserting sustainability in a practical way, in the institution's activities. The disclosed results showed that HEI adopt attitudes that meet the global context, both in its institutional actions, including the practice of the courses offered to its target audience, and in its image in the community. Thus, through the printed documents analysis and information available in the corporate website of the HEIs studied - National Service of Commercial Education (SENAC/SC) and Educational Society of Santa Catarina (SOCIESC), it was possible to identify that both organizations adopt actions and practices for the inclusion of sustainability in its institutional activities, which responds readily to the general purpose of this study.
\end{abstract}

Keywords: Sustainability. Higher Education. SENAC. SOCIESC.

\title{
1 INTRODUÇÃO
}

As discussões sobre sustentabilidade e desenvolvimento sustentável vêm chamando a atenção dos governos, das empresas e das universidades nos últimos anos. Essas organizações estão percebendo que a sustentabilidade não é um modismo empresarial ou um conjunto de ações isoladas visando à melhoria de sua reputação. Ao contrário, estão tomando consciência de que a sustentabilidade é uma necessidade imposta pela sociedade, incorporando-a em seus conceitos e princípios, bem como na gestão de suas operações (PEDROSO, 2007).

Essas discussões fizeram emergir preocupações socioambientais em organizações dos mais diversos segmentos, assim como em Instituições de Ensino Superior (IES). Por serem organizações disseminadoras de conhecimento, estas precisam refletir continuamente sobre o seu papel na preservação do meio ambiente, desenvolvendo iniciativas que permitam criar ambientes educacionais social e ambientalmente responsáveis.

Embora a sustentabilidade e a responsabilidade social já estejam inseridas no contexto de algumas organizações educacionais, seja nos currículos ou nas ações de cunho prático, sua presença ainda é "tímida" e necessita de expansão. Conciliar os princípios de desenvolvimento sustentável com as práticas de gestão educacional é um desafio, já que requer a conscientização e o comprometimento de todos os atores envolvidos no processo.

No âmbito das IES, docentes, discentes e corpo administrativo devem estar conscientes da importância de suas ações para a melhoria do meio ambiente, pois não basta inserir em seus currículos temas relacionados à sustentabilidade: é necessário que suas ações tenham reflexos na melhoria do meio ambiente e da sustentabilidade. As IES que aderem às dimensões de sustentabilidade ambiental, social e econômica formarão alunos capazes de gerar sustentabilidade, não só em sua vida profissional, mas também na sociedade onde estão inseridos, contribuindo para o desenvolvimento de uma economia sustentável e um meio ambiente mais saudável para as futuras gerações.

Nesse sentido, Araújo (2004) destaca que o papel da educação superior nas discussões sobre sustentabilidade vai além da relação ensino/aprendizagem vista em sala de aula, uma vez que ela avança para projetos extraclasse, envolvendo a comunidade do entorno e visando a soluções efetivas para a população local.

Diante disso, o objetivo do presente estudo consiste em identificar de que forma as IES estão inserindo a sustentabilidade, de maneira prática, em suas atividades institucionais. Para alcançar esse intento, este estudo está centrado na discussão acerca da relação entre os conceitos de 
sustentabilidade e as práticas realizadas por duas IES de Santa Catarina. As instituições escolhidas como objeto de estudo foram o Serviço Nacional de Aprendizagem Comercial (SENAC/SC) e a Sociedade Educacional de Santa Catarina (SOCIESC), em função da proximidade que dois dos autores desta pesquisa possuem com tais instituições, já que fazem parte do seu quadro de colaboradores.

Alguns objetivos específicos foram propostos para desenvolver este estudo: a) realizar uma reflexão acerca da relação entre os conceitos de Sustentabilidade, Educação e IES; b) apresentar as instituições de ensino estudadas por meio de um breve histórico sobre ambas; c) evidenciar como a sustentabilidade está inserida nas atividades dessas instituições, identificando as ações adotadas para este fim.

Para isso, este estudo apresenta a seguinte estrutura, além desta seção introdutória: em um primeiro momento, apresentam-se os construtos teóricos relacionados à sustentabilidade e sua aplicação em IES; em seguida, discorre-se acerca dos aspectos metodológicos que nortearam o desenvolvimento deste trabalho; na seção seguinte, são analisados os dados obtidos visando ao atendimento dos objetivos; e, por fim, apresentam-se as considerações finais, com o intuito de refletir sobre as contribuições emergentes desta pesquisa.

\section{SUSTENTABILIDADE}

O conceito de sustentabilidade vem sendo amplamente utilizado em diferentes abordagens teóricas. Partindo da sua própria amplitude, é possível ter uma ideia da complexidade de percepções e visões que este tema proporciona.

O conceito de desenvolvimento sustentável tornou-se conhecido e de uso generalizado após a publicação do relatório Brundtland, documento que resultou dos trabalhos de uma comissão da Organização das Nações Unidas (ONU), a Comissão Mundial sobre Meio Ambiente e Desenvolvimento (CMMAD), em 1987. De acordo com esse relatório, conhecido como Nosso Futuro Comum, desenvolvimento e meio ambiente devem ser complementares: não se rejeita a ideia de crescimento econômico, mas mostra-se a necessidade de busca por novas estratégias de desenvolvimento e novas tecnologias que tenham por base a sustentabilidade e a expansão dos recursos ambientais (CMMAD, 1988).

A sustentabilidade é definida, assim, como um enfoque de desenvolvimento socioeconômico orientado para: a satisfação de necessidades básicas; o reconhecimento do papel fundamental que a autonomia cultural desempenha nesses processos de mudança; e o oferecimento de um conjunto de critérios para avaliar a pertinência de ações mais específicas. Ao interligar economia, tecnologia e sociedade, a noção de desenvolvimento sustentável parte, desse modo, da necessidade de critérios de eficiência econômica para que os objetivos sejam alcançados, mas destaca que os benefícios do desenvolvimento devem ser equitativamente distribuídos (SACHS, 2000).

Para Lima (2003), a definição de desenvolvimento sustentável veiculada pelo Relatório Brundtland permite uma pluralidade de leituras, incluindo desde um sentido avançado de desenvolvimento, associado à justiça socioambiental e à renovação ética, até uma perspectiva conservadora de crescimento econômico ao qual se acrescentou uma variável ecológica. A esse respeito, Locatelli (2000, p. 297) menciona que, "ao contrário dos anseios e necessidades do homem, que podem ser consideradas como ilimitados, os recursos naturais disponíveis não o são". Nesse sentido, Penna (1999, p. 130) reforça que "grande parte das questões ambientais e sociais baseiam-se no equilíbrio abastecimento versus demanda. Embora não se sabia com precisão os seus limites, o abastecimento (de qualquer coisa) é seguramente limitado, enquanto a demanda pode ser ilimitada. Não há limites intrínsecos à demanda dos seres humanos".

Frien e Winfree (2014), por sua vez, salientam que a indústria da construção civil está 
contribuindo para a construção de uma agenda para a sustentabilidade por meio das diversas estratégias para melhorar a eficiência energética na concepção de materiais e no funcionamento das condições dos edifícios. O estudo de caso que estes autores desenvolveram na Austrália permitiu constatar que alguns projetos pilotos têm sido relevantes, a exemplo do desenvolvimento de um sistema de gestão da informação, em que a fábrica realiza a produção de componentes e monta as peças na própria construção, indicando que a ênfase em competências transversais desses coadjuvantes pioneiros reforça a agenda de sustentabilidade e as competências verdes.

Nesse contexto, o consumo, até para suprir as necessidades básicas, vem tomando direcionamentos sustentáveis. O estudo realizado por Niva et al. (2014) em quatro países nórdicos analisa em que medida as pessoas possuem padrões de consumo de alimentos que coadunam com o discurso sobre a sustentabilidade. Como contribuição, esse estudo identificou que a maioria dos cidadãos analisados são adeptos a fazer mudanças sustentáveis no seu consumo de alimentos, embora essas práticas não estejam muito bem-estabelecidas. Apesar de o percentual de pessoas que ainda não realizam práticas de consumo sustentáveis ser relativamente elevado, estas afirmam estarem dispostas a realizar atividades voltadas à preparação de alimentos e ao consumo de alimentos mais sustentáveis.

Já Souza, Casotti e Lemme (2013) estudaram o consumo consciente como determinante da sustentabilidade empresarial, retratando, nos resultados, a reação dos consumidores quanto aos métodos de criação industrial de animais e aos selos de certificação de alimentos. Os resultados da pesquisa demonstraram que ter acesso às informações sobre práticas utilizadas no processo produtivo pode implicar, por parte dos consumidores, mudanças negativas para a indústria e o varejo, tais como redução de consumo e migração para substitutos. Por parte das empresas, no entanto, esses achados podem ser vistos como oportunidade de antecipação a uma nova consciência crítica, trazida à tona pela economia da informação, ou mesmo como oportunidade de atender aos anseios de grupos de consumidores mais preocupados com a ética e com a sustentabilidade.

A utilização de práticas sustentáveis pelas empresas, cada vez mais, pode ser visualizada nos relatórios anuais das organizações. A tendência voltada à sustentabilidade na produção e no consumo vem se difundindo, o que instiga as organizações a divulgarem as práticas mais utilizadas nesse sentido. O estudo de Dimitru e Jinga (2015), realizado em uma companhia farmacêutica japonesa, analisou os relatórios anuais dessa organização, evidenciando as principais práticas sustentáveis adotadas, tais como, a utilização de energia renovável, a reutilização de água e criação de logística reversa. Estes relatórios permitem à sociedade identificar a responsabilidade e o comprometimento sustentável das organizações.

\subsection{Sustentabilidade e educação}

A prática político-pedagógica relacionada à sustentabilidade possibilita o desenvolvimento e a escolha de estratégias de ação que venham a contribuir para a construção do processo de cidadania e para a melhoria da qualidade de vida da população. Tendo como objetivo formar a consciência dos cidadãos, de modo a levar à adoção de comportamentos ambientalmente adequados, investindo nos recursos e processos ecológicos do meio ambiente, a educação ambiental deve transformar-se em ação.

Nesse sentido, a produção de conhecimento precisa necessariamente contemplar as inter-relações do meio natural com o social, incluindo a análise dos determinantes dessas relações, do papel dos diversos atores envolvidos e das formas de organização social que aumentam o poder das ações condizentes com um novo perfil de desenvolvimento, com ênfase, principalmente, nas práticas sustentáveis voltadas às dimensões social e ambiental (PELICIONI, 1998; JACOBI, 2003). 
Observa-se, na educação destinada à sustentabilidade, uma tendência para destacar a necessidade de mudanças de atitudes e comportamentos individuais em detrimento de mudanças que envolvem processos políticos e econômicos. Assim, os problemas socioambientais aparecem mais relacionados à esfera privada que à esfera pública e supõem uma desresponsabilização dos agentes coletivos públicos e privados, como, por exemplo, o Estado e as corporações globais (LIMA, 2003).

Construir, portanto, uma educação ambiental complexa, capaz de responder a problemas igualmente complexos, implica ir além de uma "sustentabilidade de mercado" reprodutivista, fragmentária e reducionista. Pressupõe, assim, a capacidade de aprender, criar e exercitar novas concepções e práticas de vida, de educação e de convivência - individual social e ambiental - que permitam substituir os velhos modelos em esgotamento (LIMA, 2003).

Um estudo elaborado por Mulready-Shick e Flanagan (2014) procurou avaliar a sustentabilidade de unidades educacionais. Os autores constataram que as interações e os comportamentos que indicavam sustentabilidade são derivados de interações participantes bem-sucedidas, em que há mudança de papéis com base no respeito mútuo, colaboração entre parceiros, trabalho dentro de sistemas adaptativos complexos e construção de relacionamentos e parcerias. Sobretudo, as parcerias de educação para a sustentabilidade maduras dependem da implementação de rotinas, reforçando, reconhecendo e recompensando atividades. $O$ nível de sucesso das ações identificadas pelos autores apresenta relação direta com a base estrutural e conceitual sustentável e serve de apoio aos indivíduos que, de alguma forma, atuam na disseminação da sustentabilidade.

Na percepção de Ralph e Stubbs (2014), para as universidades abordarem de forma abrangente a temática sustentabilidade é necessário incluir uma abordagem de "aprender para a sustentabilidade" em todos os aspectos das operações institucionais de forma sinérgica. Por meio da aplicação de entrevistas semiestruturadas, a pesquisa de Ralph e Stubbs (2014) investigou os fatores que influenciam a integração da sustentabilidade nas operações das atividades de ensino de universidades da Austrália e da Inglaterra. Os resultados evidenciaram que os indivíduos comprometidos com a meta de um mundo mais sustentável desempenharam um papel vital no sucesso da integração da sustentabilidade ambiental nas universidades.

Os fatores críticos para que as universidades realizem mudanças transformacionais necessárias para incorporar a sustentabilidade ambiental estão associados a: um ambiente político forte; recursos destinados a tais mudanças; incentivos de lideres; e advogados da sustentabilidade ambiental. Ressalta-se, assim, que educar e construir a consciência do pessoal universitário acerca da importância da sustentabilidade ambiental para as gerações futuras foi o fator-chave para a obtenção de sucesso.

\subsection{Sustentabilidade e IES}

O principal desafio do estudo da sustentabilidade e sua aplicação nas IES compreende a ambiguidade e diversidade da definição de sustentabilidade no currículo acadêmico. A compreensão e a interpretação do termo sustentabilidade e a ideia de "aprendizagem para a sustentabilidade" variam muito dentro do ensino superior. A maioria das IES tem conseguido apenas pequenos avanços incrementais na direção do fortalecimento de uma agenda educacional para a questão da sustentabilidade, sendo confrontadas com a complexidade do assunto e com uma incorporada resistência à mudança (JACOBI; RAUFFLET; ARRUDA, 2011).

Jacobi, Raufflet e Arruda (2011), em seus estudos, objetivaram contribuir para o debate sobre o papel da educação superior, na medida em que se observa um significativo aumento do número de IES que apresentam efetiva motivação para formar estudantes com conhecimento e habilidades necessários para colocar a sustentabilidade no centro de suas futuras atividades de gestão. Diante dis- 
so, Munaretto e Busanello (2014) estudaram de que modo as práticas de gestão ambiental são incorporadas e desenvolvidas nos projetos pedagógicos dos cursos de graduação de uma IES, verificando que em nenhum dos 12 projetos analisados apresenta a inserção da sustentabilidade articulada com o plano de desenvolvimento institucional e o projeto pedagógico da instituição.

Não somente nas práticas pedagógicas das IES pode ser identificada a sustentabilidade, mas também no processo de gestão das próprias instituições. Trigo, Lima e Oliveira (2014) desenvolveram em seus estudos indicadores visando mensurar o índice de adesão à sustentabilidade de instituições de ensino. O estudo, testado e avaliado em uma instituição de ensino do Rio de Janeiro, objetiva fomentar nas instituições de ensino a adoção de práticas de mensuração de seus esforços sustentáveis, direcionadas à tríade da educação - ensino, pesquisa e extensão.

Durante a última década, muitos programas de graduação, pós-graduação, especialização e extensão em negócios têm inserido módulos, cursos e componentes de sustentabilidade em seus currículos. Além disso, muitos fóruns foram estabelecidos para que educadores de gestão e negócios pudessem trocar e discutir experiências e, de forma mais ampla, refletir sobre tópicos relacionados às questões da sustentabilidade no ensino superior (JACOBI; RAUFFLET; ARRUDA, 2011).

Garcia, Kevany e Huisingh (2006) abordam em suas pesquisas a inclusão do desenvolvimento sustentável nos programas educacionais do ensino superior. Trazem relatos de experiências de entrevistados em trabalhar em equipes interdisciplinares com foco na educação, pesquisa e extensão, destacando a importância de acelerar o ritmo com que as IES incentivam e apoiam os valores, os conhecimentos e as ações para ajudar seus alunos a transformar a sociedade, alcançando, assim, padrões sustentáveis. Dentre as principais constatações evidenciadas pelos autores, destaca-se a necessidade de engajamento do ensino com a prática e da superação da resistência à mudança dentro e fora da academia.

A promoção da interdisciplinaridade como uma condição para a educação da sustentabilidade tem encontrado muita resistência nas instituições, seja por razões administrativas, seja pela relutância de os docentes formados em uma visão disciplinar se engajarem com a interdisciplinaridade e com abordagens mais práticas relacionadas com a educação para a sustentabilidade (JACOBI; RAUFFLET; ARRUDA, 2011).

As barreiras enfrentadas para que se incorpore uma consciência sustentável no ambiente das IES, muitas vezes, passam pelo crivo do pensamento de que o desenvolvimento sustentável é apenas uma moda ou que é relativo somente às questões ambientais. Essa dificuldade de entendimento do que é desenvolvimento sustentável, às vezes, está presente na alta administração das instituições, fazendo com que questões essenciais relacionadas à sustentabilidade não recebam a atenção necessária devido à burocracia, sendo tratadas como mais um processo administrativo, limitado pelos interesses econômicos (BRANDLI et al., 2012).

Nesse contexto, torna-se importante a medição, por meio de indicadores, do envolvimento da universidade com a sustentabilidade a partir do desenvolvimento de um quadro geral que possibilite avaliar sua situação atual ou seu progresso. É importante, assim, que as instituições disseminem as mudanças implantadas em prol da sustentabilidade e avaliem sua efetividade, inspirando outras instituições e atuando como um acelerador.

O papel de destaque assumido pelas IES no processo de desenvolvimento tecnológico, na preparação de estudantes e no fornecimento de informações e conhecimento pode e deve ser utilizado também para construir o desenvolvimento de uma sociedade sustentável e justa. Para que isso aconteça, entretanto, torna-se indispensável que essas organizações comecem a incorporar os princípios e as práticas da sustentabilidade, seja para iniciar um processo de conscientização em todos os seus níveis, atingindo professores, funcionários e alunos, seja para tomar 
decisões fundamentais sobre planejamento, treinamento, operações ou atividades comuns em suas áreas físicas (TAUCHEN, 2006; BRANDLI et al., 2012).

Um programa de educação para o desenvolvimento sustentável exige um reexame da política educacional, a fim de enfocar a aquisição de conhecimentos, competências, perspectivas e valores relacionados com a sustentabilidade. Para isso, é necessário revisar os objetivos e conteúdos dos currículos para desenvolver uma compreensão interdisciplinar acerca da sustentabilidade social, econômica e ambiental, revisando as metodologias recomendadas e obrigatórias em matéria de ensino, aprendizagem e avaliação (UNESCO, 2005).

O tema sustentabilidade deverá permear todas as disciplinas, inserindo a preocupação com o desenvolvimento sustentável no exercício da prática profissional e da cidadania dos alunos. Contudo, ações em nível institucional também precisam ser feitas, tanto nos cursos quanto nas instituições de ensino, para que mudanças efetivas sejam implementadas e para que se acelere o percurso rumo à sustentabilidade (PALMA; ALVES; SILVA, 2013).

No processo de implementação da sustentabilidade no currículo de administração, por exemplo, correm-se diversos riscos e desafios. Alguns se referem à reprodução da lógica do atual sistema de produção e consumo no âmbito da própria disciplina, impulsionado por metas a cumprir, conteúdos a ministrar, dentre outros fatores. Outros são mais difíceis de lidar, como a própria compreensão do âmago da sustentabilidade, que, como mencionado, é uma palavra polissêmica, carregada de diversos sentidos (GONÇALVES-DIAS; HERRERA; CRUZ, 2013).

É preciso levar em conta, sobretudo, que um dos objetivos da educação consiste em criar cidadãos responsáveis que podem compreender adequadamente os problemas enfrentados pelas suas sociedades e então agir para ajudar a resolvê-los. Tal comportamento pode ser promovido por meio de uma educação que facilite o conhecimento especializado sobre questões sociais, alimente a capacidade de pensar criticamente e permita a aquisição das habilidades necessárias para, proativamente, procurar soluções possíveis (ROY et al., 2014).

Tendo isso em vista, levantam-se as seguintes conjecturas para este estudo, considerando o referencial teórico acerca da trajetória da sustentabilidade nas dimensões ambiental, social e econômica:

- conjectura 1 - as IES pesquisadas conhecem, aplicam e avaliam seu desempenho por meio de ações de sustentabilidade devido a questões de exigência legal ou de mercado;

- conjectura 2 - as IES pesquisadas conhecem, aplicam e avaliam seu desempenho por meio de ações de sustentabilidade por questões de princípios e por acreditarem realmente nestes;

- conjectura 3 - as IES pesquisadas estão preparadas para as ações de sustentabilidade que utilizam e conscientizadas sobre estas;

- conjectura 4 - as IES pesquisadas possuem ações de sustentabilidade somente com o intuito de promover marketing verde.

É importante ressaltar que as diferentes abordagens citadas servem apenas para orientar a reflexão e a discussão neste estudo. Não há pretensão de esgotar completamente o tema em questão.

\section{METODOLOGIA}

O presente estudo foi desenvolvido no período de janeiro a fevereiro de 2014 e procurou analisar as ações sustentáveis de duas Instituições de Ensino Superior (IES) de Santa Catarina: o Serviço Na- 
cional de Aprendizagem Comercial (SENAC/SC) e a Sociedade Educacional de Santa Catarina (SOCIESC).

Do ponto de vista dos objetivos propostos, a pesquisa realizada caracteriza-se como descritiva, a qual, segundo Cooper e Schindler (2011), pode ser utilizada com o propósito de descrever características de grupos, descobrir ou verificar a existência de relação entre variáveis ou, ainda, estimar a proporção de elementos em uma população específica que tenham determinadas características ou comportamentos. Pesquisas descritivas não respondem bem o porquê dos fatores, embora possam associar certos resultados a grupos de respondentes. Além disso, podem ou não ter potencial para gerar importantes inferências, sendo bastante utilizadas devido ao seu caráter de versatilidade (COOPER; SCHINDLER, 2011).

Quanto à abordagem do problema, esta pesquisa é qualitativa. Richardson (1999, p. 80) menciona que "os estudos que empregam uma metodologia qualitativa podem descrever a complexidade de determinado problema, analisar a interação de certas variáveis, compreender e classificar processos dinâmicos vividos por grupos sociais".

A coleta de dados foi realizada com o amparo de consulta e análise de documentos institucionais e informações disponíveis nas páginas oficiais das instituições que evidenciam as ações em relação à sustentabilidade. Além disso, foi aplicado um roteiro de entrevista para três diretores: um da SOCIESC e dois do SENAC/SC (de unidades de ensino localizadas em regiões geográficas distintas). O roteiro contemplava as seguintes indagações: qual o entendimento sobre o conceito de sustentabilidade; de que forma a instituição de ensino incorpora as práticas de sustentabilidade no dia a dia; que estratégias devem ser adotadas para criar uma prática de educação para a sustentabilidade na instituição; como a instituição de ensino ensina a sustentabilidade para os seus estudantes; a IES conhece, aplica e avalia seu desempenho relativo a ações de sustentabilidade por questões de exigência legal ou de mercado; as IES conhece, aplica e avalia seu desempenho referente a ações de sustentabilidade por questões de princípios e por acreditarem realmente nestes; a IES está preparada para as ações de sustentabilidade que utilizam e conscientizada sobre estas; e a IES possui ações de sustentabilidade somente com o intuito de promover marketing verde.

Para a realização deste estudo, foram acessados os registros dos projetos voltados à sustentabilidade realizados no âmbito das IES, que apresentam informações como: objetivos, finalidade e público-alvo. Além destes, os registros que mostram as ações voltadas à sustentabilidade foram identificados por meio de relatórios internos que informam, por exemplo, a quantidade de papel arrecadado e reciclado nas IES, a existência de arrecadação de pilhas e baterias e listas de presença de palestras de conscientização promovidas pelas instituições.

Do site das IES, foram extraídas informações acerca dos projetos de extensão realizados em que a sustentabilidade está inserida, bem como de projetos de pesquisa que envolvem, em seu planejamento e em sua execução, docentes e discentes e têm como beneficiários a própria comunidade. Os sites também apresentam relatórios de extensão universitária, que mostram os indicadores das ações executadas, além do balanço social, um dos mais importantes documentos de registro das ações realizadas.

Quanto aos procedimentos da pesquisa, a técnica aplicada neste trabalho é a análise descritiva, que, segundo Santos e Parra Filho (1998), visa identificar as diferentes formas de um fenômeno de dados ordenados e pré-classificados.

O processo da pesquisa é apresentado no Quadro 1, exposto a seguir. 
Quadro 1: Metodologia utilizada e respectivas características do trabalho

\begin{tabular}{|c|c|c|c|c|}
\hline Objetivos da pesquisa & $\begin{array}{c}\text { Fonte de coleta } \\
\text { de dados }\end{array}$ & $\begin{array}{c}\text { Aspectos abor- } \\
\text { dados }\end{array}$ & $\begin{array}{l}\text { Sistematização } \\
\text { da informação }\end{array}$ & $\begin{array}{c}\text { Bases constitutivas } \\
\text { para análise }\end{array}$ \\
\hline $\begin{array}{l}\text { Realizar uma abordagem } \\
\text { acerca da relação entre os } \\
\text { conceitos de sustentabili- } \\
\text { dade, educação e IES. }\end{array}$ & $\begin{array}{l}\text { Levantamento } \\
\text { bibliográfico; } \\
\text { Roteiro de en- } \\
\text { trevista. }\end{array}$ & $\begin{array}{l}\text { Conceitos de } \\
\text { sustentabilida- } \\
\text { de, educação } \\
\text { e IES. }\end{array}$ & $\begin{array}{l}\text { Descrição suces- } \\
\text { siva em parágra- } \\
\text { fos. }\end{array}$ & $\begin{array}{l}\text { Brandli (2012); } \\
\text { Sachs (2008); } \\
\text { Jacobi, Raufflet e Ar- } \\
\text { ruda (2011); } \\
\text { Lima (2003). }\end{array}$ \\
\hline $\begin{array}{l}\text { Apresentar as instituições } \\
\text { de ensino estudadas e as } \\
\text { ações desenvolvidas por } \\
\text { ambas no que tange à sus- } \\
\text { tentabilidade. }\end{array}$ & $\begin{array}{c}\text { Documentos } \\
\text { institucionais; } \\
\text { Página oficial } \\
\text { das IES na inter- } \\
\text { net. } \\
\text { Roteiro de en- } \\
\text { trevista. }\end{array}$ & \begin{tabular}{|} 
Relação dos \\
conceitos estu- \\
dados com as \\
ações realizadas \\
pelas IES.
\end{tabular} & $\begin{array}{l}\text { Breve apresen- } \\
\text { tação das IES e } \\
\text { pesquisa sobre } \\
\text { suas ações. }\end{array}$ & - \\
\hline $\begin{array}{l}\text { Analisar como a sustenta- } \\
\text { bilidade está inserida nas } \\
\text { atividades das instituições, } \\
\text { identificando as ações } \\
\text { adotadas para este fim. }\end{array}$ & $\begin{array}{l}\text { Registros insti- } \\
\text { tucionais; } \\
\text { Página oficial } \\
\text { das IES na inter- } \\
\text { net. } \\
\text { Roteiro de en- } \\
\text { trevista. }\end{array}$ & $\begin{array}{l}\text { Histórico e } \\
\text { ações realizadas } \\
\text { pelo SENAC/SC } \\
\text { e pela SOCIESC }\end{array}$ & $\begin{array}{l}\text { Descrição das } \\
\text { principais ações } \\
\text { realizadas por } \\
\text { cada IES. }\end{array}$ & $\begin{array}{c}\text { Brandli (2012); } \\
\text { Sachs (2008). }\end{array}$ \\
\hline
\end{tabular}

Fonte: os autores

A partir da coleta de dados, foi realizada uma análise de acordo com os aspectos abordados pelos conceitos de sustentabilidade, levando em consideração a análise de conteúdo/documentos relacionados às instituições de ensino. Foram identificadas, assim, as principais ações de sustentabilidade desenvolvidas pelas IES nas dimensões econômica, social e ambiental.

\section{APRESENTAÇÃO E ANÁLISE DOS DADOS}

Por meio dos dados coletados, foi possível elaborar um breve histórico de cada Instituição de Ensino Superior (IES) e identificar algumas ações sustentáveis por elas promovidas, demonstrando o compromisso com o futuro das gerações. Este estudo possibilitou, também, elencar alguns projetos realizados com o intuito de premiar os acadêmicos que desenvolveram ações que agregassem valor à sua formação e que pudessem contribuir para as organizações e a sociedade, conforme apresentado a seguir.

\subsection{O SENAC/SC e a gestão para a sustentabilidade}

O ano de 1947 ficou marcado na história de Santa Catarina como a data de criação do Serviço Nacional de Aprendizagem Comercial (SENAC) no estado. Desde então, empresários do comércio de bens, serviços e turismo e o povo catarinense desenvolveram suas habilidades profissionais por meio de cursos e atividades realizadas pela instituição em Santa Catarina. O crescimento da organização acompanhou a evolução econômica de Santa Catarina, e hoje o SENAC está em todas as regiões do estado com uma Administração Regional e 27 pontos fixos de atendimento divididos em: oito Faculdades de Tecnologia, três Centros Especializados, 16 Centros de Educação Profissional; e quatro Unidades Móveis.

A organização oferece cursos em oito eixos tecnológicos, conhecidos como áreas de atuação: ambiente, saúde e segurança; apoio educacional; gestão e negócios; hospitalidade e lazer; informação e comunicação; infraestrutura; produção cultural e design; e recursos naturais. 
Esses eixos possibilitam ao empresariado e à sociedade contar com cursos de desenvolvimento profissional em diversas áreas, contribuindo com o crescimento de Santa Catarina (SENAC, 2014).

O SENAC em Santa Catarina tem um compromisso com o meio ambiente em suas rotinas e em seus processos. A sustentabilidade está inserida no dia a dia das unidades por meio de ações internas e externas, que promovem o respeito à natureza e a conscientização de colaboradores e alunos.

A Faculdade SENAC, em suas oito unidades- Florianópolis, Blumenau, Chapecó, Criciúma, Caçador, Jaraguá do Sul, São Miguel do Oeste e Tubarão -, oferece cursos tecnólogos como Processos Gerenciais, Gestão Comercial, Gestão da Tecnologia da Informação, Gestão de Recursos Humanos, Logística, Análise e Desenvolvimento de Sistemas, Gestão da Qualidade, Gastronomia e Gestão Financeira, os quais têm em suas unidades curriculares disciplinas com foco em sustentabilidade ambiental, social e econômica (SENAC, 2014).

O SENAC em Santa Catarina integra, pela segunda vez consecutiva, a lista das 150 meIhores empresas para trabalhar, segundo o ranking da revista Você/S.A. Com uma marca consolidada por 60 anos de trabalho, a instituição expande a sua atuação no estado e investe na gestão de pessoas. O SENAC recebeu a nota de 81,2 no Índice de Qualidade no Ambiente de Trabalho, que representa a avaliação dos colaboradores e inclui critérios como: identificação com a empresa, satisfação e motivação. No balanço do ranking de 2013, a publicação constatou a força de boas ferramentas para a gestão de recursos humanos.

Um dos diferenciais para os colaboradores é o Projeto Trilha, que ajuda o funcionário a entender o seu espaço na empresa e quais são os passos necessários para chegar a cargos mais altos. A instituição também desenvolve um programa de preparação para a aposentadoria, o Viver Bem (SENAC, 2014).

\subsubsection{Ações de Sustentabilidade nas Unidades do SENAC/SC}

Todas as unidades do SENAC de Santa Catarina estimulam, apoiam e desenvolvem ações de sustentabilidade junto aos seus colaboradores, gestores e alunos de todos os níveis de ensino - sejam eles básicos, técnicos, tecnólogos ou de pós-graduação. A seguir, são relatadas algumas das ações realizadas por algumas das unidades do SENAC de Santa Catarina (SENAC, 2014):

- Florianópolis - as ações são planejadas e executadas pela Comissão Recicle Ideias, que é formado por colaboradores, orientadores e alunos. Dentre os projetos realizados, estão a coleta de pilhas e baterias, o trabalho sobre compostagem na Associação dos Funcionários Fiscais de Santa Catarina junto ao projeto Jovem Aprendiz e a parceria com a biblioteca para a arrecadação de produtos de higiene e limpeza;

- Caçador - todo o papel ofício fotocopiado ou impresso é utilizado para rascunho (inclusive pelos alunos) e também para a confecção de bloquinhos de anotação. Os jornais são doados para entidades de reciclagem, e as revistas de generalidades são levadas para asilos, hospitais e outras entidades assistenciais que atendem a população. Além disso, são colocadas em prática medidas para a economia de energia e o aproveitamento de materiais utilizados em eventos;

- Blumenau - todo o material utilizado diariamente é separado para a reciclagem. Também é organizado um passeio ciclístico para a conscientização da população sobre mobilidade urbana, transporte sustentável, meio ambiente e importância das ciclovias; 
- Brusque - em 2013, realizou ações socioambientais como palestras e intervenções urbanas. O projeto Curativos Urbanos, por exemplo, foi realizado com os alunos do curso técnico de Design de Interiores do Programa Nacional de Acesso ao Ensino Técnico e Emprego (Pronatec), espalhando nas ruas, calçadas e árvores da cidade cartazes e curativos confeccionados pelos estudantes;

- Rio do Sul - na biblioteca a economia de papel é perseguida continuamente. Folhas são impressas dos dois lados, sempre que possível, e todas que apresentam algum problema de impressão são reutilizadas. Além disso, a separação dos resíduos é estimulada por meio de lixeiras específicas;

- Joinville - é ponto de coleta de diversos materiais que não devem ser misturados ao lixo comum. Um deles é o óleo de cozinha, que, para o descarte, deve ser acondicionado depois de frio em uma garrafa pet. Da unidade, o material segue para empresas licenciadas. Outro material recolhido em Joinville são chapas de raios- $X$, que possuem metais pesados altamente poluidores que, em contato com o solo, atingem o lençol freático e contaminam a água, podendo entrar na cadeia alimentar. As chapas são coletadas em uma caixa de papelão e recolhidas por uma empresa de Curitiba, que recicla o material produzindo embalagens com os plásticos e utilizando a prata na criação de joias. Além disso, os resíduos da unidade são separados por tipo de material, e uma campanha de conscientização foi feita para que os funcionários trocassem os copinhos de plástico por canecas;

- Criciúma - a biblioteca vende para uma empresa de reciclagem todo o papel que descarta (desde picotados, papéis de impressão, caixas que vêm dos fornecedores de livros etc.) e, com o recurso da venda, compra livros usados de literatura no sebo. Outros setores da unidade também contribuem, enviando para a biblioteca papéis que seriam destinados para o lixo.

- Tubarão -todo o papel impresso é utilizado para rascunho e confecção de blocos de anotações. Além disso, há lixeiras de coleta seletiva, controle do uso de energia, incentivo à caminhada para realização de tarefas de pequena distância e reutilização de envelopes. Para evitar o descarte de material bibliográfico, exemplares são disponibilizados a outras bibliotecas e expostos na mesa de doações. Ressalta-se, ainda, que as torneiras são temporizadas para a redução do consumo de água.

- Xanxerê - foram distribuídos squeezes para cada aluno e colaborador da unidade. Dessa forma, não são utilizados nem fornecidos copos descartáveis. Outra ação realizada no local é a conscientização dos alunos sobre a importância da reciclagem dos materiais.

As entrevistas realizadas complementaram essa descrição das ações em prol da sustentabilidade e das práticas desenvolvidas pela unidade de ensino do SENAC, ao elucidar que o diretor da unidade pesquisada entende que o termo sustentabilidade se refere a ações que promovem a utilização consciente dos recursos, sem excessos e sem desperdícios, tendo como enfoque a responsabilidade social, econômica e ambiental. Dessa forma, o diretor em questão entende que o SENAC incorpora as práticas de sustentabilidade por meio de utilização consciente dos recursos, evitando o desperdício e dando destino correto aos resíduos. $\mathrm{O}$ entrevistado citou como exemplos: a não utilização de copos descartáveis pelos funcionários (corpo administrativo e professores), uma vez que todos receberam um squeeze e uma caneca, o que reduziu em $50 \%$ o uso de copos plásticos descartáveis (que chegava a 5.000 unidades/mês); 
As estratégias que o diretor do SENAC entende como relevantes para a criação de estratégias direcionadas para a enculturação de uma prática de educação para a sustentabilidade estão associadas à inclusão do tema responsabilidade ambiental nos cursos superiores de Processos Gerenciais, Gestão da Qualidade e Design de Interiores, em que os professores vinculam essa temática ao conteúdo ministrado; à disseminação das informações sobre o tema; e à criação de campanhas de conscientização, inclusive por meio da Comissão Interna de Prevenção de Acidentes (CIPA). Dessa forma, o processo de ensino da sustentabilidade para os alunos ocorre porque existem conteúdos relacionados abordados nos cursos, bem como a realização de atividades práticas.

Quando indagado sobre a existência de avaliação de desempenho acerca da sustentabilidade por exigência do mercado ou por causa de requisitos legais, o entrevistado salientou que no caso do SENAC isso ocorre por vontade própria, uma vez que não há uma cobrança. Assim, devido ao fato de a instituição trabalhar com profissionais que possuem um alto grau de informação/conhecimento/formação, as práticas sustentáveis começam a ser incorporadas. Não há ações efetivas de avaliação de desempenho, mas existem projetos que devem ser implantados em 2016 em função do curso superior de Gestão da Qualidade. O diretor ressaltou, também, que as IES não estão totalmente preparadas para o desenvolvimento das ações de sustentabilidade, pois, como é algo espontâneo, ainda falta conhecimento e conscientização acerca dessas práticas para que elas serem incorporadas na vida das pessoas.

Na entrevista realizada com o diretor da outra unidade do SENAC, o entrevistado afirmou que sustentabilidade são ações que buscam garantir as necessidades das pessoas sem comprometer as próximas gerações, bem como promover o desenvolvimento econômico sem prejudicar o meio ambiente. Mencionou, ainda, que é adotando hábitos de controle do uso de recursos naturais e economizando e reciclando materiais que a instituição incorporará as práticas de sustentabilidade no dia a dia.

Quando indagado sobre as estratégias para criar uma prática de educação para a sustentabilidade na instituição, o entrevistado afirmou que inovar na gestão da organização voltada para a preservação do meio ambiente e promover alternativas de bem-estar para as pessoas são boas estratégias, visto que pouco do conhecimento sobre a sustentabilidade é efetivamente utilizado na prática. Assim, para os estudantes, devem ser promovidas campanhas de conscientização e inclusão social e ministrados componentes curriculares que abordem o tema.

\subsection{A SOCIESC e a gestão para a sustentabilidade}

A Sociedade Educacional de Santa Catarina (SOCIESC) é uma instituição educacional, cultural e tecnológica que está presente, em Santa Catarina, nas cidades de Joinville, Blumenau, São Bento do Sul, Balneário Camboriú e Florianópolis e, no Paraná, na cidade de Curitiba. Atua no ensino fundamental, fundamental bilíngue, médio, técnico, de graduação e de pós-graduação lato sensu e stricto sensu (especializações em MBA e mestrados reconhecidos pela Coordenação de Aperfeiçoamento de Pessoal de Nível Superior - CAPES), em cursos de extensão e capacitação empresarial e no ensino a distância.

Além disso, oferece serviços de engenharia, consultoria e gestão para o desenvolvimento de novas tecnologias para empresas nacionais e internacionais. Os serviços ofertados contam com uma moderna infraestrutura em laboratórios de metrologia, química e mecânica, por meio das áreas de Gestão Tecnológica \& Pesquisa e Desenvolvimento, Ferramentaria, Fundição e Tratamento Térmico. A SOCIESC possui um sistema de gestão da qualidade que atende aos requisitos da norma NBR ISO9001, devidamente certificado pelo Bureau Veritas (BV). 


\subsubsection{Ações de sustentabilidade nas unidades da SOCIESC}

Na SOCIESC, a sustentabilidade faz parte da cultura da organização, estando presente na sua Missão, na sua Visão e nos seus Valores. Ser uma organização de excelência e referência em educação e inovação tecnológica é a visão que a empresa possui com relação à sua forma de atuação no mercado, tendo como objetivo contribuir para o desenvolvimento humano e da comunidade.

Possui como valor o crescimento de forma significativa e sustentável, atuando na educação, cultura e tecnologia com ética e valorizando o desenvolvimento do ser humano. Pretende, assim, despertar os talentos e criar um ambiente que favoreça o exercício da cidadania.

A SOCIESC aderiu, para o alinhamento de seus projetos, a três grandes eixos norteadores: Cultura e Comunidade; Educação e Conhecimento; e Tecnologia. Em todas as unidades da SOCIESC, são desenvolvidos vários projetos, que abrangem alunos, docentes, discentes, colaboradores e comunidade externa.

A unidade de Joinville possui mais de 20 projetos em andamento, divididos entre os três grandes eixos mencionados. No eixo de Cultura e Comunidade, podem-se destacar alguns projetos como Régua de Inclusão de Deficientes Visuais, Levantamento e Diagnóstico do Patrimônio Histórico Cultural de Joinville, Museu de Fundição e Violência Doméstica e seus Reflexos no Ângulo Empresarial.

No eixo de Educação e Conhecimento, a que pertence a maior parte dos projetos, podemse destacar os projetos Planejando meu Futuro, VIVAS -Viva Intensamente Valorizando a Sustentabilidade, Contabilidade Infantil, Contabilidade Doméstica, Laboratório de Projetos e Construindo Sonhos Partilhando Conhecimentos. Esses projetos têm como objetivo aliar os conhecimentos e a aprendizagem adquiridas na IES com sua aplicação na sociedade, a fim de identificar melhorias e promover o aprimoramento de situações corriqueiras e cotidianas da comunidade local.

Já os projetos a serem destacados no eixo da Tecnologia são: Olimpíadas de Ciência e Tecnologia, Experimentos Científicos e Gestão Tecnológica para empresa, dentre outros. Esses projetos possuem estrutura voltada à inovação e ao aprimoramento de produtos e serviços.

Dentre todos os projetos da unidade de Joinville, pode-se destacar o projeto Régua da Inclusão para Deficientes Visuais, que tem como objetivo criar uma régua multifuncional para proporcionar a inclusão educacional do portador de deficiência visual. Essa régua obteve, em setembro de 2013, o reconhecimento da Secretaria Municipal de Educação de Joinville/SC por meio do ofício n. $327-G A B$ e já foi apresentada em diversos eventos. Recentemente, passou a integrar o catálogo de portfólio de tecnologias assistivas, promovido pelo Fórum Nacional de Gestores de Inovação e Transferência de Tecnologia (FORTEC). O catálogo é composto de produtos e processos desenvolvidos por instituições de ensino e centros de pesquisas.

Na unidade da SOCIESC em Balneário Camboriú, é possível destacar cinco projetos ativos. Direcionados ao eixo da Educação e Conhecimento, destacam-se os projetos Controle Patrimonial, Blog Empreender SOCIESC, Ultrapassando Fronteiras - Informática Básica e Papo Cabeça!. O projeto Gestão e Responsabilidade Social: um olhar para a Casa da Criança e do Adolescente de Balneário Camboriú possui cunho social e é voltado para a comunidade local.

A unidade de Blumenau conta atualmente com 12 projetos, e a grande maioria é voltada ao eixo de Cultura e Comunidade. Os projetos desenvolvidos são IBES na Comunidade, ICOM IBES, Responsabilidade Social e Psicologia, Apoio ao Bem Nascer, NPJ IBES, Declara IBES, Jornal Laboratório, Núcleo de Práticas Jurídicas, PAC, Serviços de Psicologia IBES, VIVAS - Viva Intensamente Valorizando a Sustentabilidade e 3R's - Reduzir, Reutilizar e Reciclar.

Por fim, na unidade de Florianópolis, os projetos são mais variados com relação aos eixos de atuação da SOCIESC. Os projetos 3R's - Reduzir, Reutilizar e Reciclar, Ação Doar Sangue 
e Ergonomia quadro a quadro classificam-se no eixo de Cultura e Comunidade. Os projetos MIDI - Mídias Digitais e PDCT - Projeto de Divulgação Científica e Tecnológica e a Revista de Iniciação Científica e Extensão da SOCIESC, Integrata, possuem caráter de Inovação e Tecnologia, enquanto os projetos ATLAS, CICLOS, Formatando o Conhecimento, dentre outros, classificam-se no eixo de Educação e Conhecimento.

Quando indagada em relação ao seu entendimento sobre o conceito de sustentabilidade, a diretora da SOCIESC, unidade Florianópolis, respondeu que ela reflete a autossustentação econômica, ambiental e social, com postura ética, trazendo benefícios para a sociedade e a comunidade na qual a instituição de ensino está inserida, bem como rentabilidade para a instituição, que é privada sem fins lucrativos e reinveste seus resultados nos projetos de pesquisa e extensão e em sua equipe.

A diretora informou que a IES incorpora as práticas de sustentabilidade no seu dia a dia participando do movimento "Nós podemos Santa Catarina", que é formado por empresas, por organizações sociais e pelo poder público com o objetivo de promover a melhoria da qualidade de vida da população catarinense atendendo aos compromissos assinados no termo de adesão em prol dos oito Objetivos de Desenvolvimento do Milênio.

Além disso, a IES busca disseminar a sustentabilidade por meio do desenvolvimento de projetos de extensão e iniciação científica, envolvendo temáticas de sustentabilidade, inclusão social e preservação ambiental. Uma campanha de reciclagem institucional - Projeto 3R's -, a inclusão de disciplinas nas grades dos cursos de graduação e pós-graduação e a realização de palestras sobre sustentabilidade nos eventos realizados para os alunos e a comunidade em geral complementam as ações voltadas à sustentabilidade.

Ao responder sobre como a instituição de ensino ensina a sustentabilidade para os seus estudantes, a diretora informou que esse processo ocorre de forma interdisciplinar, contextualizada e aplicada a projetos. Já sobreo conhecimento, a aplicação e avaliação do seu desempenho por meio de ações de sustentabilidade, a diretora afirmou que, mais que atender a todas as exigências legais, as ações realizadas pela instituição voltam-se à preocupação com a sustentabilidade em si, uma vez que tais ações são muito mais amplas do que o que está previsto em lei. Assim, a sustentabilidade está inserida nos valores da instituição, que são:

- crescimento e reconhecimento - crescer de forma significativa e sustentada, tendo como base o reconhecimento da comunidade;

- responsabilidade social - atuar na educação, cultura e tecnologia, com ética e visão de sustentabilidade;

- valorização das pessoas - valorizar o desenvolvimento do ser humano, despertando os talentos e criando um ambiente que favoreça o exercício da cidadania.

Por fim, ao ser indagada sobre a existência de ações voltadas ao marketing verde, a diretora respondeu que a instituição não tem explorado o marketing verde por ser uma instituição privada e sem fins lucrativos, que não tem capital aberto, acionistas ou investidores.

\subsection{Discussão dos resultados}

O contexto mundial atual fala, trata, age e pensa de forma sustentável. Cada vez mais, encontram-se empresas, organizações, órgãos públicos, organizações não governamentais (ONGs), escolas e a própria sociedade voltando-se ao conhecimento, estudo e planejamento de ações sustentáveis que levem a humanidade para um melhor caminho de desenvolvimento. 
Os resultados encontrados na análise de conteúdo realizada nas IES analisadas levam a perceber que estas traçam uma linha comum de ação que vem ao encontro desse contexto mundial, tanto em suas ações institucionais, quanto na prática dos cursos oferecidos ao seu público-alvo e divulgação de sua imagem perante a comunidade.

Grande parte dos projetos desenvolvidos pelas IES tem seus objetivos voltados para a disseminação do conceito de sustentabilidade, incentivando a utilização de alternativas sustentáveis no dia a dia. As duas instituições analisadas contemplam, assim, as disposições de Jacobi, Raufflet e Arruda (2011), quando dispõem que é muito importante formar estudantes com conhecimento e habilidades necessárias para colocar a sustentabilidade no centro de suas futuras atividades de gestão.

O desenvolvimento das atividades realizadas pelo SENAC e pela SOCIESC evidencia o início de um processo de mudança comportamental e estrutural. Grandes desafios, como perceber um consenso sobre o que é efetivamente a sustentabilidade e a falta de interesse e de comprometimento, já estão em processo de aprimoramento ou até mesmo superados. Porém, outros desafios apresentados por Thomas (2004), como as limitadas recompensas e a falta de experiência e de apoio financeiro, ainda precisam ser superados e entendidos tendo em vista o retorno que a aplicação de projetos sustentáveis pode estar proporcionando para as atuais e futuras gerações.

Porém, isso somente tomará corpo quando a sociedade entender a importância da manutenção da sustentabilidade. Pelicioni (1998) e Jacobi (2003) destacam que é necessária a interação social com o meio natural, promovendo fatores como análise de determinantes, identificando os reflexos dessas interações e o papel dos diversos atores envolvidos no processo, permitindo, assim, evidenciar suas responsabilidades com o meio onde estão inseridos. Com isso, é possível fazer conexões com os projetos realizados pelas IES analisadas, em que os acadêmicos vão à sociedade com o objetivo de aplicar as teorias estudadas, envolvendo nesse processo a população e desenvolvendo novas alternativas e possibilidades de melhorias nas questões rotineiras da sociedade.

Pode-se, ainda, confrontar a base teórica utilizada neste estudo com as práticas das IES analisadas, especialmente com relação à teoria apresentada por Brandli (2012) e Tauchen (2006), que tratam da importância da participação de todos os níveis de colaboradores nas decisões e nos projetos, o que fica evidente em diversos projetos das instituições. Identificou-se, também, que as instituições analisadas não desenvolvem projetos de sustentabilidade no próprio processo gestão, o que permite a realização de outro estudo aprofundado para a implantação de um sistema de gestão sustentável integrado, visando à busca do aprimoramento da sustentabilidade neste tipo de organização.

É lícito afirmar, desse modo, que a presente análise instigou a realização de proposições para que as duas organizações pesquisadas possam melhorar o seu nível de sustentabilidade. Desse modo, sugere-se para ambas as organizações:

- criar indicadores econômicos, sociais e ambientais para mensurar o seu nível de sustentabilidade. Esses indicadores podem estar pautados nas diretrizes da Global Reporting Initiative (GRI), que são reconhecidos internacionalmente e permitem comparabilidade entre diferentes organizações;

- transformar a sustentabilidade em um elemento estratégico da organização, para que, a partir dos indicadores mensurados, possa ser utilizadas na gestão estratégica e organizacional das instituições de ensino pesquisadas; 
- criar um programa de educação para a sustentabilidade, que dê ênfase às práticas sociais, ambientais e econômicas que contribuam para criar organizações longevas e perenes. Cita-se como exemplo: humanização do trabalho; inclusão de cotas para idosos; inserção do menor aprendiz, de pessoas com deficiência, de indígenas e tribais e de ex presidiários na seleção de colaboradores; práticas trabalhistas baseadas em normas universais como a OSHAS 18.001, a SA 8.000 (social accountability); relato dos indicadores de concessão de benefícios regularmente a empregados de tempo integral da organização, como, por exemplo, seguro de vida, plano de saúde, auxílio-deficiência e invalidez, licença-maternidade/paternidade, fundo de pensão, plano de aquisição de ações; monitoramento e registro dos tipos de lesões, da taxa de lesões, da taxa de doenças ocupacionais, dos dias perdidos, da taxa de absenteísmo e do número de óbitos relacionados ao trabalho para o total de trabalhadores (ou seja, empregados próprios e terceirizados);

- realização de treinamentos e conscientização referente à saúde, segurança e ergonomia no ambiente de trabalho; à prevenção de acidentes no ambiente de trabaIho; e aos direitos humanos relevantes para as operações da organização; relatar os processos formais de queixas e reclamações por parte de comunidades locais;

- monitorar o número de queixar e reclamações de clientes e fornecedores;

- relatar os riscos significativos relacionados à corrupção identificados com base em avaliações de riscos e discorrer sobre a importância da ética no contexto organizacional;

- comunicar as políticas e os procedimentos anticorrupção adotados pela organização;

- comunicar para as partes interessadas o seu desempenho sustentável via relatórios específicos (relatório de sustentabilidade e balanço social);

- investir em estratégias de marketing verde, ecoinovação e ecodesign;

- estimular a adequação da gestão dos resíduos sólidos às premissas preconizadas pela Política Nacional de Resíduos Sólidos;

- criar uma horta ecológica e estimular crianças e adolescentes a produzirem hortaliças e legumes e a incorporar essas práticas no dia a dia das famílias;

- ensinar alternativas de aproveitamento e transformação dos resíduos orgânicos produzidos pelas famílias em subprodutos que sirvam de adubo para plantas ornamentais e hortas urbanas;

- comunicar princípios e valores éticos das instituições de ensino, seja nos processos internos ou nas negociações com as partes interessadas (clientes, fornecedores, sociedade e acionistas);

- relatar os indicadores de logística reversa adotados;

- inserir práticas de ecoeficiência, de reciclo da água, de reuso da água, de tratamento de efluentes, de controle da poluição, de biotecnologia; e de energias limpas;

- mitigar os impactos ambientais gerados;

- adotar a contabilidade ambiental;

- adotar indicadores de monitoramento do índice de retrabalho e reprocesso;

- dar ênfase a gastos com fornecedores locais.

Sobretudo, a proposição de ações para a melhoria contínua está pautada na intenção de contribuir para que as dimensões econômica, social e ambiental possam ser plenamente atendidas nas organizações pesquisadas e para que se criem organizações sustentáveis e conscientes do seu papel social no contexto em que estão inseridas. Isso está associado à criação de uma 
cultura que compreende, valoriza e incorpora práticas de sustentabilidade no seu dia a dia, o que nem sempre é fácil de ser operacionalizado, mas contribuirá para promover organizações comprometidas com a perenidade do planeta, a formação de pessoas cidadãs e a mitigação do passivo ambiental que geram.

\section{CONSIDERAÇÕES FINAIS}

Por meio da análise de conteúdo de documentos impressos e virtuais das Instituições de Ensino Superior (IES) selecionadas, Serviço Nacional de Aprendizagem Comercial (SENAC/SC) e Sociedade Educacional de Santa Catarina (SOCIESC), percebeu-se que as duas organizações se utilizam de ações e práticas para a inserção da sustentabilidade em suas atividades institucionais, o que responde prontamente ao objetivo geral deste estudo.

No desenvolvimento dos itens que compõem este artigo, foi possível descrever e alcançar os objetivos específicos com êxito, já que a estrutura do referido artigo está constituída primeiramente pelo referencial teórico quanto a conceitos de sustentabilidade e sua relação com a educação e as IES, respondendo, assim, o primeiro objetivo específico. Por conseguinte, o segundo objetivo específico também foi alcançado quando se apresentam as instituições de ensino estudadas, por meio de um breve histórico. Por fim, evidenciar como a sustentabilidade está inserida nas atividades das instituições, identificando as ações adotadas para este fim, foi o terceiro objetivo específico traçado, que também foi alcançado.

As principais constatações deste estudo estão balizadas nas conjecturas criadas a partir da pesquisa realizada. Com relação à primeira hipótese (conjectura 1 - as IES pesquisadas conhecem, aplicam e avaliam seu desempenho relativo a ações de sustentabilidade por questões de exigência legal ou de mercado), observou-se que, em nenhum documento pesquisado, encontram-se evidências de que as IES pesquisadas aplicam ações de sustentabilidade por puro cumprimento de deveres impostos por algum órgão regulador ou pela própria sociedade, negando esta hipótese.

Com relação à segunda conjectura (as IES pesquisadas conhecem, aplicam e avaliam seu desempenho quanto a ações de sustentabilidade por questões de princípios e por acreditarem realmente nestes) e à terceira conjectura (as IES pesquisadas estão preparadas para ações de sustentabilidade que utilizam e conscientizadas sobre estas), nota-se que os conteúdos pesquisados são claros em demonstrar o conhecimento das IES quanto à importância de planejar, aplicar e avaliar ações de sustentabilidade, bem como de divulgar tais ações aos stakeholders para firmar sua imagem na sociedade como empresas comprometidas sustentavelmente, validando também estas hipóteses.

Já no caso da quarta e última hipótese levantada neste estudo (as IES pesquisadas possuem ações de sustentabilidade somente com o intuito de marketing verde), pode-se afirmar que não é uma hipótese válida, pois, em nenhum conteúdo pesquisado, encontraram-se indícios de que o objetivo das ações de sustentabilidade dessas instituições seja propagarem suas atividades na mídia.

A principal contribuição deste estudo está associada à percepção de que as IES não só se preocupam com a sustentabilidade, mas estão dispostas a atuar de forma sustentável, assim como planejam ou já dispõem de unidades curriculares focando o tema. Isso demonstra que as IES estão preparadas e prontas para atuar em um mercado cada vez mais exigente, que não busca somente informação ou conhecimento, mas um serviço de qualidade, que ofereça algum diferencial.

Este estudo oferece, assim, informações importantes sobre o tema, tanto para as IES que queiram conhecer mais sobre a prática sustentável quanto para os futuros acadêmicos, que, ao escolher em qual IES irão realizar sua formação profissional, podem levar em conta os diferenciais de atuação das IES no que diz respeito às suas ações de sustentabilidade. 
Verifica-se como limitação do presente estudo o fato de ter sido realizado somente em duas IES, até mesmo porque o estado de Santa Catarina possui mais de 70 IES com sedes físicas, além das IES virtuais que atuam em todo o Brasil. Outro fator limitante foi de ordem geográfica, já que a ênfase do estudo foi em organizações localizadas no estado de Santa Catarina. Recomenda-se, dessa forma, para estudos futuros, aumentar o número de IES pesquisadas neste estado da união ou comparar as ações de sustentabilidade do estado com ações de IES de outras unidades federativas.

\section{REFERENCIAS}

ARAÚJO, M. I. O. A universidade e a formação de professores para a educação ambiental. Revista Brasileira de Educação Ambiental, Brasília, n. 0, p.71-78, nov. 2004. Disponível em: <www.seer.furg.br/revbea/article/ download/4080/2434> Acesso em: 20 jun. 2014.

BARDIN, I. Análise de conteúdo. Lisboa: Edições Setenta, 1994, 226 p.

BRANDLI, L. L. et al. Avaliação da presença da sustentabilidade ambiental no ensino dos cursos de graduação da universidade de passo fundo. Revista Avaliação, Campinas, v. 17, n. 2, p. 433-454, 2012. Disponível em: <http:// periodicos.uniso.br/ojs/index.php?journal=avaliacao\&page $=$ article \&op=view \&path\%5B\%5D=763> Acesso em: 20 jun. 2014.

CMMAD - Comissão Mundial sobre Meio Ambiente e Desenvolvimento. Nosso Futuro Comum. Rio de Janeiro: Ed. FGV, 1988.

COOPER, D. R.; SCHINDLER, P. S. Métodos de pesquisa em administração. 10. ed. Porto Alegre: Bookman, 2011.

DIMITRU, M.; JINGS, G. Integrated reporting practice for sustainable business: a case study. Audit. Financiar, n. 7, v. 13, p. 117-125, 2015. Disponível em: <> Acesso em: 08 jul. 2015.

DRYZEK, J. The politics of the earth. Oxford: Oxford University Press, 2005. Disponível em: <http://www.humanecologyreview.org/ pastissues/her51/51bookreviews.pdf> Acesso em: 20 jun. 2014.

FIEN, J; WINFREE, T. Drivers of change in construction training: how significant is the sustainability agenda? Prospects, v. 44, p. 211-219, 2014. Disponível em: <> Acesso em: 05 jul. 2015.

FOLADORI, G. Limites do desenvolvimento sustentável. Campinas: UNICAMP, 2001. Disponível em: <http://periodicos.ufes.br/ temporalis/article/view/2913> Acesso em: 20 jun. 2014.

GARCIA, F. J. L.; KEVANY, K. HUISINGH, D. Sustainability in higher education: whats is happening? Journal of Cleaner Production, $v$. 14, p. 757-760, 2006. Disponível em: <http:// www.sciencedirect.com/science/article/pii/ S095965260600014X> Acesso em: 08 jul. 2015.

GOERGEN, P. Educação Superior: entre formação e performance. Revista Avaliação, v. 13, n. 3, nov. p. 809-815, 2008. Disponível em: <http://www.scielo.br/scielo.php?pid=S141440772008000300010\&script $=$ sci_arttex> Acesso em: 20 jun. 2014.

GONÇALVES-DIAS, S. L. F., HERRERA, C. B., CRUZ, M. T. de S. Desafios e dilemas para inserir "Sustentabilidade" nos currículos de administração: um estudo de caso. RAM RevistadeAdministraçãoMackenzie, SãoPaulo, v. 14, n. 3, 2013. Edição especial. Disponível em: <http://www.scielo.br/scielo.php?pid=S167869712013000300006\&script=sci_arttext> Acesso em: 20 jun. 2014.

JACOBI, P. R. Educação ambiental, cidadania e sustentabilidade. Cadernos de Pesquisa, $n$. 118, 2003. Disponível em: <http://www.scielo. $\mathrm{br} / \mathrm{pdf} / \mathrm{cp} / \mathrm{n} 118 / 16834$. pdf $>$ Acesso em: 20 jun. 2014.

JACOBI, P. R. Educação ambiental: o desafio 
da construção de um pensamento crítico, complexo e reflexivo. Revista Educação e Pesquisa FE-USP, São Paulo, v. 31, n. 2, p. 302313, 2005. Disponível em: <http://www.scielo. $\mathrm{br} / \mathrm{pdf} / \mathrm{ep} / \mathrm{v} 31 \mathrm{n} 2 / \mathrm{a} 07 \mathrm{v} 31 \mathrm{n} 2 . \mathrm{pdf}>$ Acesso em: 20 jun. 2014.

JACOBI, P. R., RAUFFLET, E., ARRUDA, M. P. Educação para a sustentabilidade nos cursos de administração: reflexão sobre paradigmas e práticas. RAM - Revista de Administração Mackenzie, São Paulo: v. 12, n. 3, p. 21-50, 2011. Edição especial. Disponível em: <http://www.scielo.br/scielo. php?pid=S1678-69712011000300003\& script=sci_arttext>Acesso em: 20 jun. 2014.

LOCATELLI, P. A. Consumo sustentável. Revista de Direito Ambiental, São Paulo, v. 5, n. 19, p. 297-300, jul.-set, 2000. Disponível em: <http://www.rt.com.br/?sub=produto. detalhe\&id=44029> Acesso em: 20 jun. 2014.

LIMA, G. da C. O discurso da sustentabilidade e suas implicações para a educação. Revista Ambiente e Sociedade, São Paulo, v. 6, n. 2, 2003. Disponível em: <http://www.mma.gov. $\mathrm{br} /$ port/sdi/ea/deds/arqs/gustlima_ambsoc. pdf> Acesso em 20. Jun. 2014.

MULREADY-SHICK, J; FLANAGAN, K. Building the Evidence for Dedicated Education Unit Sustainability and Partnership Success. Nursing Education Perspectives, v. 35, n. 5, set.-oct, 2014. Disponível em: <http://www.nlnjournal. org/doi/pdf/10.5480/14-1379> Acesso em: 05 jul. 2015.

MUNARETTO, L. F.; BUSANELLO, S. Um estudo sobre a inserção da educação ambiental nos projetos pedagógicos dos cursos do CESNORS/ UFSM. Rev. Adm, Santa Maria, v.7, p. 24-39, set. 2014. Edição especial. Disponível em: <http://cascavel.ufsm.br/revistas/ojs-2.2.2/ index.php/reaufsm/article/view/11374> Acesso em: 08 jul. 2015.

NIVA, M.; MÄKELÄ, J.; KAHMA, N.; KJÆERNES, U. Eating Sustainably? Practices and Background
Factors of Ecological Food Consumption in Four Nordic Countries. J. Consum Policy, v. 37, p. 465-484. 2014. Disponível em: <http://link. springer.com/article/10.1007 \%2Fs10603-0149270-4\#page-1> Acesso em: 06 jul. 2015.

PALMA, L. C., ALVES, N. B., SILVA, T. N. Educação para a sustentabilidade: a construção de caminhos no instituto federal de educação, ciência e tecnologia do Rio Grande do Sul (IFRS).

RAM - Revista de Administração Mackenzie, São Paulo, v. 14, n. 3, 2013. Edição especial. Disponível em: <http://www.osorio.ifrs.edu. br/site/midias/ arquivos/201437212618370 relatorio_autoavaliacao_2014.pdf>Acesso em: 20 jun. 2014.

PELICIONI, M. C. F. Educação ambiental, qualidade de vida e sustentabilidade. Revista Saúde e Sociedade, v. 7, p. 19-31. 1998. Disponível em: <http://www.scielo.br/pdf/ sausoc/v7n2/03> Acesso em: 20 jun. 2014.

PENNA, C. G. O estado do planeta: sociedade de consumo e degradação ambiental. Rio de Janeiro: Record, 1999.

PEDROSO, M. C. Casos Sustentáveis. Revista GV-executivo, v. 6, n. 2, p. 25, 2007. Disponível em: <http://rae.fgv.br/en/gv-executivo/vol6num2-2007/casos-sustentaveis> Acesso em: 20 jun. 2014.

RALPH,M;STUBBS, W. Integratingenvironmental sustainability into universities. High Educ, v. 67, p. 71-90, 2014. Disponível em: <http:// link.springer.com/article/10.1007\%2Fs10734013-9641-9\#page-1> Acesso em: 05 jul. 2015.

RICHARDSON, R.J. Pesquisa social: métodos e técnicas. 3.ed. São Paulo: Atlas, 1999.

ROY, $A$; et al. Promoting proper education for sustainability: An exploratory study of ICT enhanced Problem Based Learning in a developing country. International Journal of Education and Development using Information and Communication Technology (IJEDICT), v. 10, n. 1, p. 70-90, 2014. Disponível 
em: $\quad<$ http://ijedict.dec.uwi.edu/viewarticle. php?id=1744> Acesso em: 05 jul. 2015.

SACHS, W. Sustainable Development. In: REDCLIFT, M.; WOODGATE, G. The International Handbook of environmental sociology. Cheltenham: Edward Elgar, p. 71-82, 2000. Disponível em: <http://www.amazon. com/International-Handbook-EnvironmentalSociology-Redclift/dp/184844088X>Acesso em: 20 jun. 2014.

SANTOS, J.A., PARRA FILHO, D. Metodologia científica. São Paulo: Futura, 1998.

SENAC. Senac Sustentável. Joinville, SC, 2014. Disponível em: <http://blog.sc.senac.br/ senac-sustentavel/> Acesso em: 04 fev. 2014.

SENAC. O Senac. 2014a. Disponível em:<http:// portal.sc.senac.br/senac/webforms/interna. aspx?campo=1115\&secao_id=18> Acesso em: 04 fev. 2014.

SOCIESC. Site oficial da SOCIESC. 2014. Disponível em: <http://www.sociesc.org.br/ pt/home/index.php> Acesso em: 04 fev. 2014.

SOCIESC. Site oficial da SOCIESC. 2014a. Disponível em: <> Acesso em: 04 fev. 2014.

SOCIESC. Blog Única. 2014. Disponível em: <http://blog.unica.br/?cat=7>Acesso em: 05 fev. 2014.

SOUZA, M. C. G. L.; CASOTTI, L. M.; LEMME, C. F. Consumo consciente como determinante da sustentabilidade empresarial: respeitar os animais pode ser um bom negócio. Rev. Adm, Santa Maria, v. 6, p. 229-246, mai. 2013. Edição especial. Disponível em: <http://cascavel.ufsm. $\mathrm{br} / \mathrm{revistas} / \mathrm{ojs}-2.2 .2 /$ index.php/reaufsm/ article/view/ 9022> Acesso em: 08 jul. 2015.

TAUCHEN, J., BRANDLI, L. L. Gestão ambiental em instituições de ensino superior: modelo para implantação em campus universitário. Revista Gestão e Produção, v. 13, n. 3, p. 503515, 2006. Disponível em: <http://www.scielo. br/pdf/gp/v13n3/11.pdf> Acesso em: 20 jun.
2014.

THOMAS, I. Sustainability in tertiary curricula: what is stopping it happening? International Journal of Sustainability in Higher Education, Melbourne, v. 5, n. 1, p. 33-47, 2004. Disponível em: <http://www.emeraldinsight. com/journals.htm ?articleid $=839825>$ Acesso em: 20 jun. 2014.

TRIGO, A. G. M.; LIMA, R. S. X.; OLIVEIRA, D. M. Índice de sustentabilidade socioambiental no ensino. Rev. Adm, Santa Maria, v. 7, p. 7-22, nov. 2014. Edição especial. Disponível em: <http://cascavel.ufsm.br/revistas/ojs-2.2.2/ index.php/reaufsm/article/ view/12771> Acesso em: 08 jul. 2015.

UNESCO. Década da educação das Nações Unidas para um desenvolvimento sustentável, 2005-2014: documento final do esquema internacional de implementação. Brasília: Unesco, 2005. 